\title{
Effects of Abdominal Hollowing During Stair Climbing on the Activations of Local Trunk Stabilizing Muscles: A Cross-Sectional Study
}

\author{
Ah Young Lee, MD, Eun Hyuk Kim, MD, Yun Woo Cho, MD, \\ Sun Oh Kwon, PT, Su Min Son, MD, Sang Ho Ahn, MD
}

Department of Physical Medicine \& Rehabilitation and Spine Center, Yeungnam University College of Medicine, Daegu, Korea

Objective To examine using surface electromyography whether stair climbing with abdominal hollowing (AH) is better at facilitating local trunk muscle activity than stair climbing without $\mathrm{AH}$.

Methods Twenty healthy men with no history of low back pain participated in the study. Surface electrodes were attached to the multifidus (MF), lumbar erector spinae, thoracic erector spinae, transverse abdominus - internal oblique abdominals (TrA-IO), external oblique abdominals (EO), and the rectus abdominis. Amplitudes of electromyographic signals were measured during stair climbing. Study participants performed maximal voluntary contractions (MVC) for each muscle in various positions to normalize the surface electromyography data.

Results AH during stair climbing resulted in significant increases in normalized MVCs in both MFs and TrA-IOs $(\mathrm{p}<0.05)$. Local trunk muscle/global trunk muscle ratios were higher during stair climbing with AH as compared with stair climbing without AH. Especially, right TrA-IO/EO and left TrA-IO/EO were significantly increased $(\mathrm{p}<0.05)$.

Conclusion Stair climbing with AH activates local trunk stabilizing muscles better than stair climbing without AH. The findings suggest that AH during stair climbing contributes to trunk muscle activation and trunk stabilization.

Keywords Stair climbing, Abdominal hollowing, Local trunk stabilizing muscles

\section{INTRODUCTION}

Chronic low back pain (LBP) is a common clinical prob-

Received May 16, 2013; Accepted August 21, 2013

Corresponding author: Sang Ho Ahn

Department of Physical Medicine and Rehabilitation, Yeungnam University College of Medicine, 170 Hyeonchung-ro, Nam-gu, Daegu 705-717, Korea

Tel: +82-53-624-8353, Fax: +82-53-624-8356, E-mail: spineahn@ynu.ac.kr

(c) This is an open-access article distributed under the terms of the Creative Commons Attribution Non-Commercial License (http://creativecommons. org/licenses/by-nc/3.0) which permits unrestricted noncommercial use, distribution, and reproduction in any medium, provided the original work is properly cited.

Copyright $\odot 2013$ by Korean Academy of Rehabilitation Medicine lem, and its treatment varies considerably from medication to physical and exercise therapies [1]. Treatment guidelines recommend numerous types of exercise for chronic LBP, but it is not clear which are most effective [2]. Aerobic exercise has been a fundamental part of low back rehabilitation programs. The rationale for the aerobic exercise on the management of LBP is based on its analgesic [3] and antidepressant [4] effects. Stair climbing is an inexpensive and natural aerobic movement and can be easily performed in everyday life [5]. Furthermore, it has many benefits; it improves cardiorespiratory fitness [5], bone mineral density [6], and balance, helps prevent falls, and prolongs independence [7]. Previous studies 
have described the effects of stair climbing on mean electromyographic activities of lower extremity and pelvic muscles [8,9]. However, the effects of stair climbing on trunk muscles remain unclear.

Bergmark classified trunk muscles as local muscles or global muscles [10], defining local muscles as those essential for stabilizing the lumbosacral spine, such as the multifidus (MF), transverse abdominus (TrA), and internal oblique abdominals (IO) [10]. Global muscles were defined as those responsible for gross movements of the trunk; these muscles include external oblique abdominals (EO) and rectus abdominis (RA) [11]. Biomechanical studies have demonstrated that trunk muscle activities during functional activities and exercise are required to maintain spinal stability [12]. Abdominal hollowing (AH) has been presented as an activity that exercises the TrA [13]. AH is used to prevent and treat LBP by enhancing local trunk muscle activity while minimizing the activities of more superficial global muscles [14]. However, the isolated activation of deep trunk muscles appears to be difficult. To address difficulties associated with performing $\mathrm{AH}$, previous researchers have used real-time ultrasound imaging techniques to provide visual feedback $[15,16]$ and shown that ultrasound images of the abdominal wall can provide immediate knowledge of performance by displaying movement and thickening of these muscles in real-time [15].

We hypothesized that stair climbing with AH more effectively facilitates local trunk stabilizing muscles than stair climbing without AH. Accordingly, we investigated the effects of AH during stair climbing on local trunk muscle facilitation using surface electromyography (EMG).

\section{MATERIALS AND METHODS}

\section{Subjects}

Twenty healthy right-handed men (age 27.9 \pm 3.09 years, height $176.3 \pm 4.15 \mathrm{~cm}$, weight $71.1 \pm 7.18 \mathrm{~kg}$, body mass index $22.92 \pm 2.56 \mathrm{~kg} / \mathrm{m}^{2}$ ) with no previous history of low back pain were included. Subjects were given comprehensive oral and written information regarding the purpose of the study, and signed a consent form, which had been approved beforehand by our Institutional Review Board.

\section{Experimental design and procedure $A H$}

Subjects were trained by a physiotherapist to perform AH maneuvers correctly. Palpation was performed as previously described [17]. Patients were asked to gently and slowly draw in the lower abdomen below the navel without moving the upper stomach, back or pelvis, while deliberately breathing in and out [18]. Subjects practiced AH with verbal and tactile feedback. For the latter, the subjects' fingers were placed medially $2 \mathrm{~cm}$ from the iliac crest until subjects were able to perform the maneuver to the satisfaction of a physiotherapist (Fig. 1). A Stabilizer
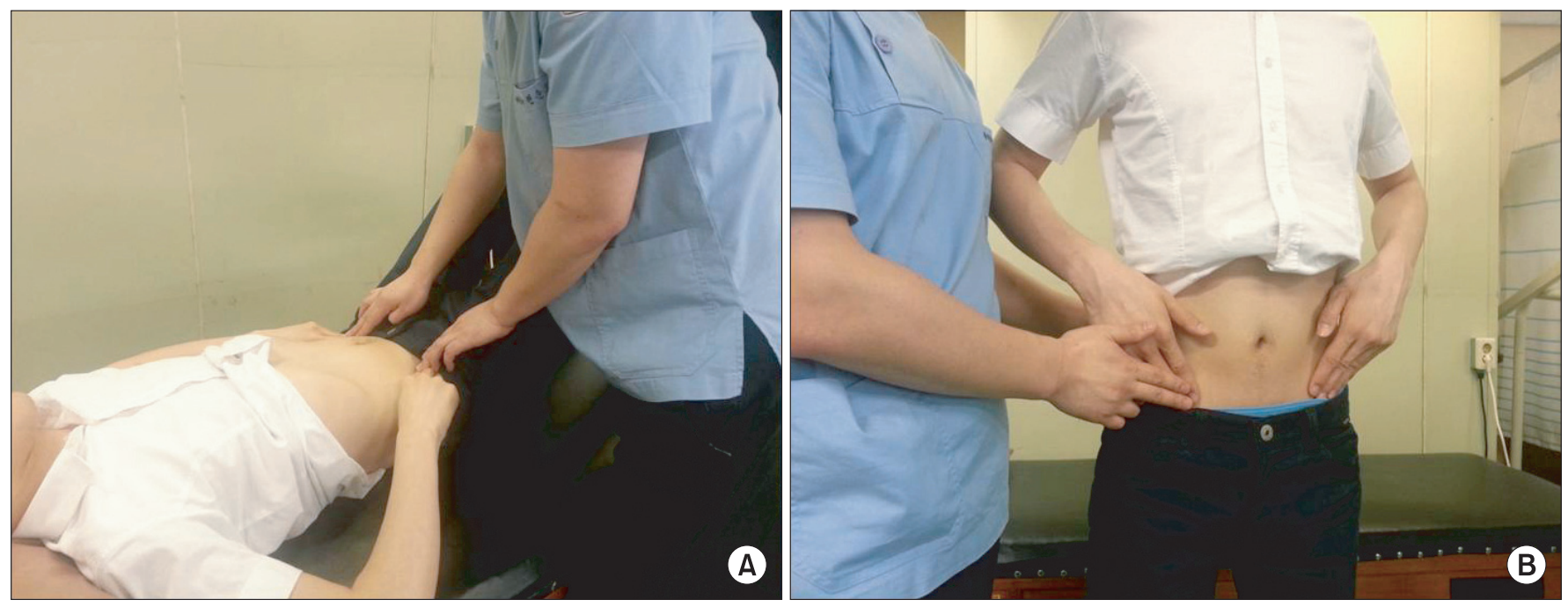

Fig. 1. Subject performing abdominal hollowing (AH) with verbal and tactile feedback. AH with verbal and tactile feedback in the supine position (A) and standing position (B). 
pressure biofeedback unit (Chattanooga Group, Hixson, TN, USA) was used to standardize maneuvers [19]. The pressure biofeedback aided the retraining of stabilizing muscles and detected movements of the lumbar spine in relation to an air-filled reservoir with the subject in a prone and supine position on a plinth, with arms to each side, and the head fully relaxed in a mold at midline with the neck straight and relaxed. In this position, a 4-10 $\mathrm{mmHg}$ reduction in basic pressure of $70 \mathrm{mmHg}$ indicates an ability to activate the TrA muscle independently of other abdominal wall muscles [15]. After supine and prone position, AH training in the supine hook lying position, the single leg slide with the contralateral leg supported position and the single leg slide with the contralateral leg unsupported position were performed (Fig. 2). To avoid inter-device differences, the same pressure biofeedback unit was used throughout the study. Real-time ultrasound feedback was provided with subjects in the supine hook lying position [20] using an Achievo CST unit (V2U Healthcare, Singapore) and a $2.0-6.0 \mathrm{MHz}$ convex array [15]. Correct AH was defined as observed thickening and lateral movement of the TrA muscle and thickening of the IO muscle, confirmed by imaging the anterolateral abdominal wall in real-time. During AH, none of the following four substitution patterns were observed: 1) contraction of the EO muscle (verified by the absence of muscle thickening by real-time ultrasound imaging and by palpation);2) minimal to no movement of the pelvis in the posterior direction as confirmed by visual inspection and palpation of the pelvis; 3 ) increased weightbearing through the heels (determined by placing a scale under the feet); and 4) deep inspiration followed by
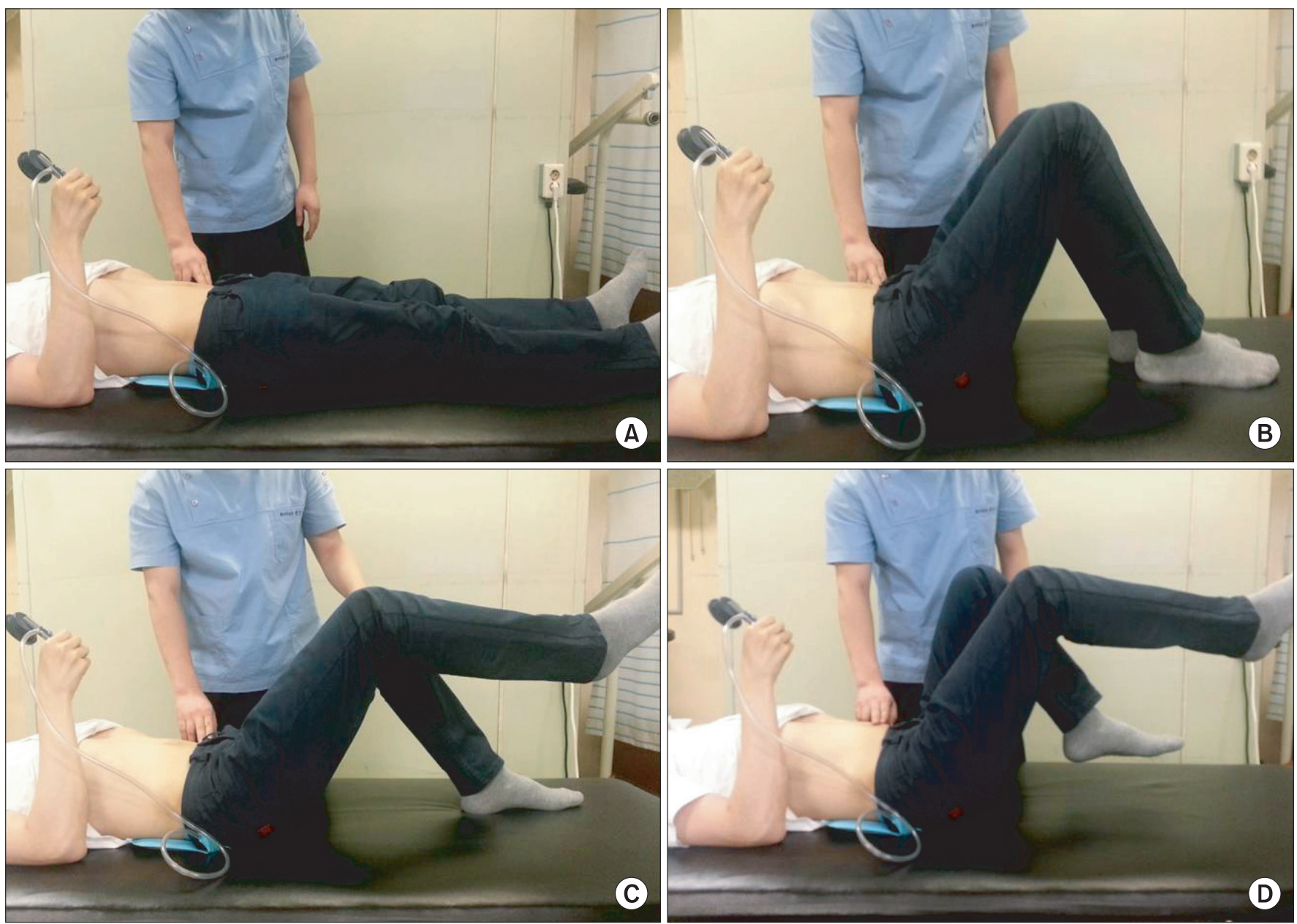

Fig. 2. Subject performing abdominal hollowing $(\mathrm{AH})$ with pressure biofeedback. AH with pressure biofeedback in the supine position (A) and supine hook lying position (B). AH with pressure biofeedback in the single leg slide with the contralateral leg supported position (C) and unsupported position (D). 
breath holding as determined by visual inspection and palpation of the anterior thorax [15]. A transducer was placed transversely across the abdominal wall along the line midway between the inferior angle of the rib cage and the iliac crest. The medial edge of the probe was placed approximately $10 \mathrm{~cm}$ from midline. However, its position as adjusted to ensure that the medial edge of the TrA was approximately $2 \mathrm{~cm}$ from the medial edge of the ultrasound image when a subject was relaxed. The angle of the transducer was revised to optimize visualization. Real-time ultrasound images were displayed on a television monitor, which was easily viewed by subjects in the supine position. Before beginning $\mathrm{AH}$, subjects were instructed to cough so they could see movements of abdominal muscles on the monitor. Subjects performed five more practice $\mathrm{AH}$ trials and received feedback regarding performance based on ultrasound imaging findings. Each trial was limited to 20-30 minutes to minimize subject fa-
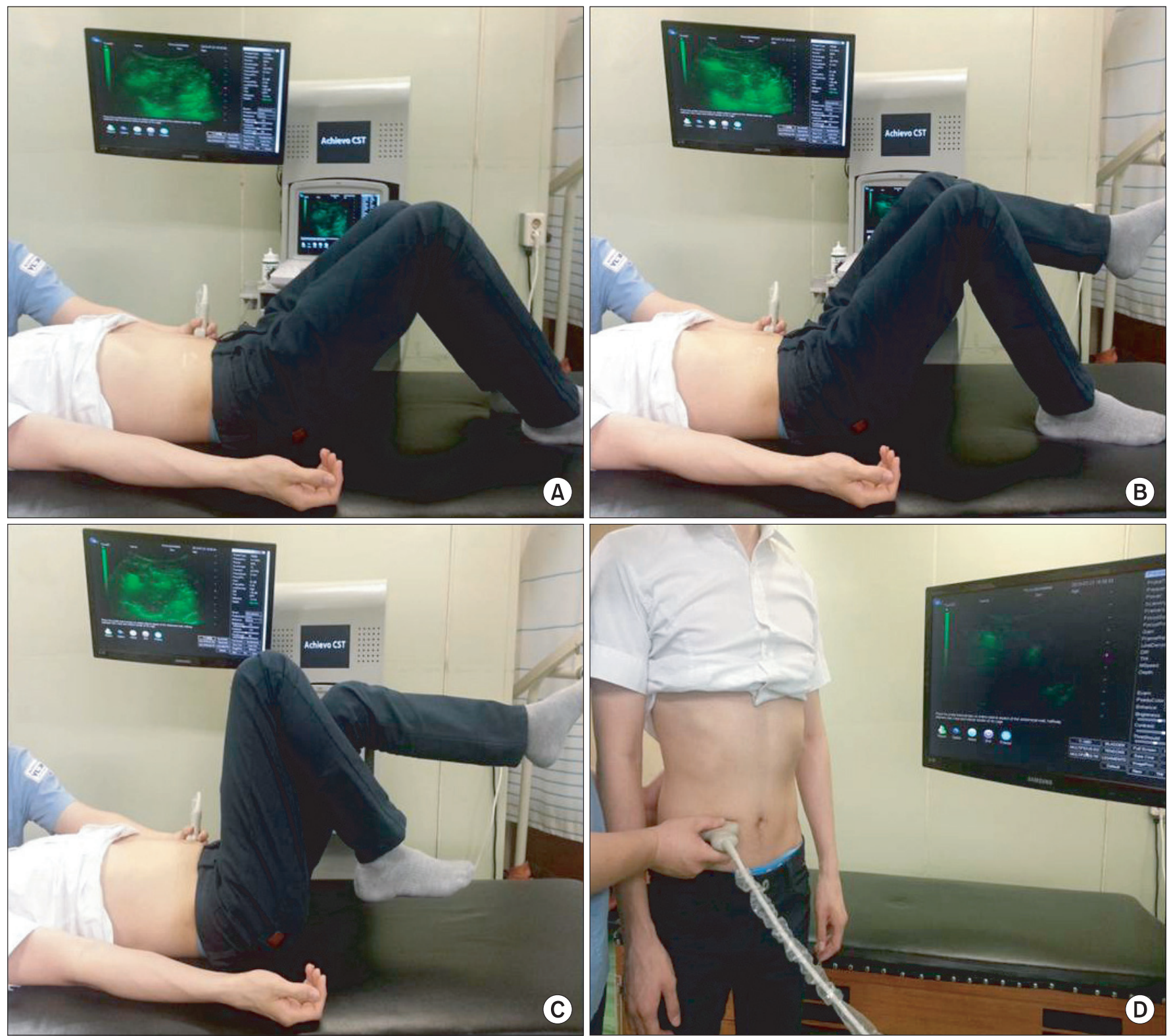

Fig. 3. Subject performing abdominal hollowing $(\mathrm{AH})$ with real-time ultrasound biofeedback. AH with real-time ultrasound biofeedback in the supine hook lying position (A), in the single leg slide with the contralateral leg supported position (B) and unsupported position (C), and in the standing position (D). 
tigue [15]. At the end of AH training in the supine hook lying position, the single leg slide with the contralateral leg supported position, and the single leg slide with the contralateral leg unsupported position were accomplished. To confirm the correct performance of AH after training in these positions, a physiotherapist observed thickening and lateral movement of the TrA muscle in the standing position [14] (Fig. 3).

\section{Data recording}

Six pairs of surface electrodes as part of the Red Dot monitoring electrode 2223 (3M Health Care, Borken, Germany) were attached while a subject stood relaxed with feet $10 \mathrm{~cm}$ apart on a flat surface. One pair of electrodes was positioned over the MF muscle $(2 \mathrm{~cm}$ lateral to the spinous process of L4) [21], one pair over the lumbar erector spinae ( $5 \mathrm{~cm}$ lateral to the $\mathrm{L} 2$ spinous process) [22], one pair over the thoracic erector spinae (TES; 2 to $4 \mathrm{~cm}$ lateral to the T12 spinous processes) [23], one pair over the EO (inferior to the rib angle aligned inferomedially toward the pubis) [24], one pair over the IO (medial to anterior superior iliac spine aligned inferomedially toward the pubis) [24], and one pair over the RA (adjacent to the umbilicus) [24] (Fig. 4).

Due to the inevitable but quantitatively unknown contribution of TrA contraction to IO recording [24], these recordings were indicated as TrA-IO [25]. In addition, a ground electrode was placed over the mid-portion of the lumbosacral junction. In each area of electrode placement, the skin was shaved and scrubbed clean with alcohol, and a disposable $\mathrm{Ag} / \mathrm{AgCl}$ surface electrode disk was positioned. An active and a reference electrode were placed $20 \mathrm{~mm}$ apart in the direction of muscle fibers on all muscles.
Surface EMG data were acquired at a sampling rate of 1,500 Hz using a TeleMyo 2400T G2 measurement system (Noraxon, Scottsdale, AZ, USA) at a fixed overall gain perchannel of 500. Prior to analysis, all raw EMG data were filtered at a band-pass of 30-500 Hz. Filtered data were rectified and smoothed using a moving window (100 ms). MyoResearch ver. 1.07 (Noraxon) was used for data processing and analysis.

EMG measurements were taken three times, and their means were used in the analysis. Root mean square (RMS) values were calculated from raw EMG data, and means of three RMS values were normalized with respect to maximal voluntary contraction (MVC) to quantify muscle activity levels, which were expressed as percentages of MVC (\%MVC). To determine MVCs, subjects were seated on a model 2000 dynamometer (Biodex Medical Systems, New York, NY, USA). After three training trials with a rest period of a few minutes, a study assistant encouraged all subjects to perform maximum isometric trunk flexions, extensions and rotations to both sides in a standardized manner. Subjects were asked to sit upright in the chair dynamometer and to repeat each exercise three times. EMG MVC data of the TrA was obtained by asking subjects to cough as hard as possible in a sitting position.

\section{Stair climbing (Fig. 5)}

Subjects climbed stairs at a natural place to permit acclimatization, participants climbed stairs carrying the EMG device. The stairs consisted of 12 steps with a rise of $0.17 \mathrm{~m}$ and a depth $0.27 \mathrm{~m}$, which were within accepted steps norms [26]. Just before stair climbing, contraction of the TrA muscle was assessed by palpation by a physiotherapist. EMG activities were recorded during stair climbing with and without $\mathrm{AH}$. To prevent abdominal

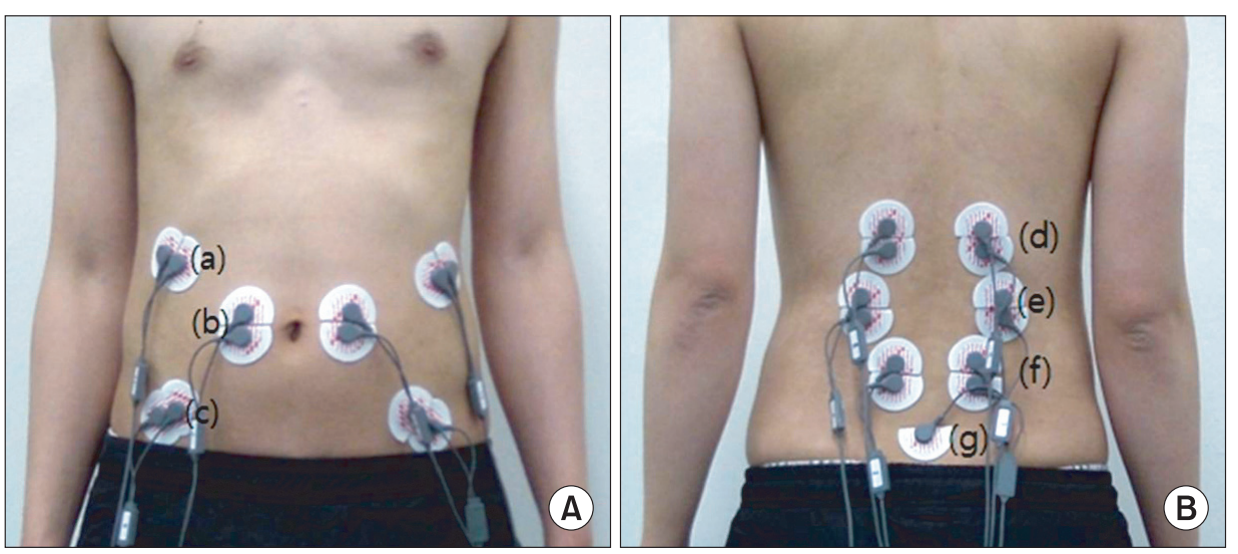

Fig. 4. Positions of surface electrodes: (A) ventral side and (B) dorsal side. (a) External oblique abdominals, (b) rectus abdominis, (c) transverse abdominus internal oblique abdominals, (d) thoracic erector spinae, (e) lumbar erector spinae, (f) multifidus, (g) ground electrode. 
muscle fatigue, a pause of at least 20 seconds was allowed between trials.

\section{Data analysis}

Changes in individual muscle activities caused by $\mathrm{AH}$ were investigated, and changes in local and global muscle activity ratios were evaluated. This assessment was conducted separately for abdominal and back muscles, that is, for TrA-IO/RA and TrA-IO/EO, and for MF/TES [27].
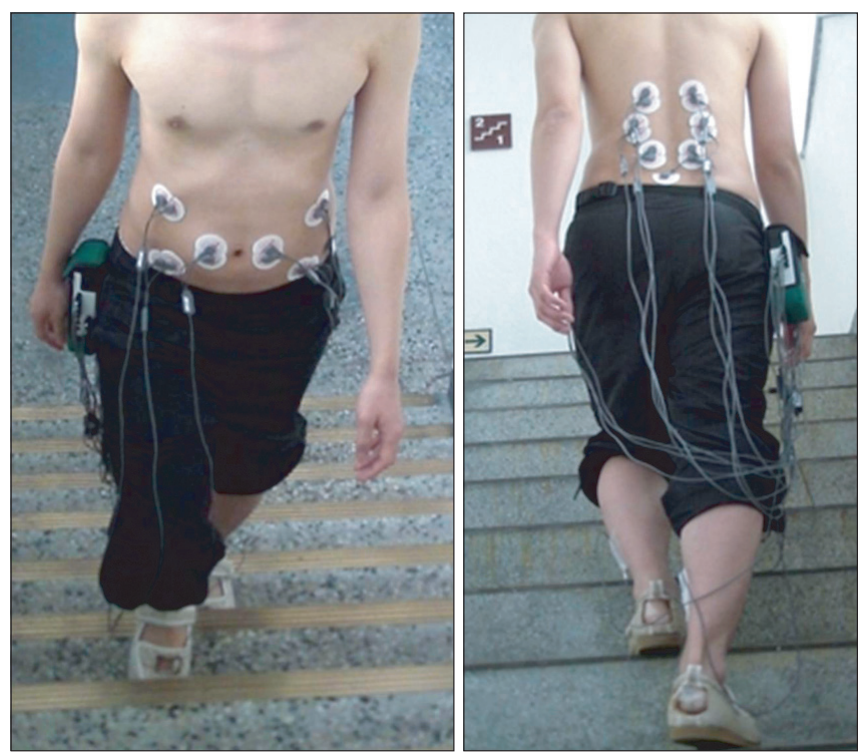

Fig. 5. Stair-climbing and recording electromyography activities with or without abdominal hollowing.

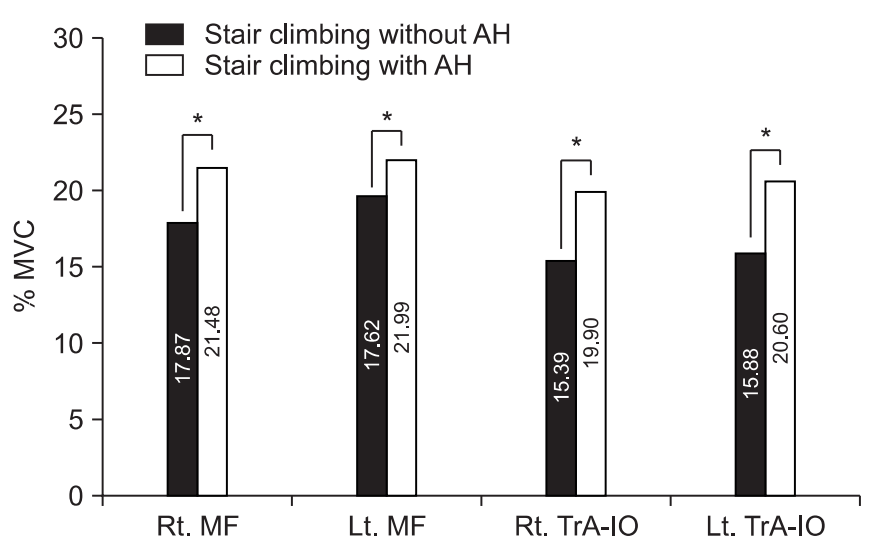

Fig. 6. Trunk muscle activities during stair climbing with or without abdominal hollowing (AH). Stair climbing with $\mathrm{AH}$ resulted in significantly more recruitment of the multifidus (MF) and transverse abdominus - internal oblique abdominal muscles (TrA/IO). ${ }^{*} \mathrm{p}<0.05$. MVC, maximal voluntary contraction; Rt., right; Lt., left.

\section{Statistical analysis}

SPSS ver. 19.0 (IBM, Armonk, NY, USA) was used for data analysis. The Kolmogorov-Smirnov test was used to assess data normality. The paired t-test was used to comparison of the activities of individual muscles and local/global muscle activity ratios calculated from data obtained during stair climbing with or without AH. Statistical significance was accepted for $p$-values $<0.05$.

\section{RESULTS}

Table 1 shows the mean values of normalized MVC data for each muscle during stair climbing. Stair climbing with AH resulted in significantly more MF and TrA-IO recruitment than stair climbing without AH (Fig. 6). However, no significant difference was observed for the other trunk muscles (Table 1). The relative activities of local trunk muscles and global trunk muscles were calculated as ratios, which are summarized in Table 2. Local trunk muscle/global trunk muscle activity ratios were higher for stair climbing with $\mathrm{AH}$, and those of TrA-IO/EO were

Table 1. Electromyographic activities of trunk muscles during stair climbing with or without $\mathrm{AH}$

\begin{tabular}{|c|c|c|c|c|}
\hline \multirow{2}{*}{ Muscle } & & \multicolumn{2}{|c|}{ Activity of muscle (\%MVC) } & \multirow{2}{*}{ p-value } \\
\hline & & Without AH & With AH & \\
\hline \multirow[t]{2}{*}{ MF } & $\mathrm{R}$ & $17.87 \pm 9.35$ & $21.48 \pm 12.55$ & $0.005^{\mathrm{a})}$ \\
\hline & $\mathrm{L}$ & $17.62 \pm 6.45$ & $21.99 \pm 10.99$ & $0.018^{\mathrm{a})}$ \\
\hline \multirow[t]{2}{*}{ LES } & $\mathrm{R}$ & $17.13 \pm 7.95$ & $18.02 \pm 7.77$ & 0.080 \\
\hline & $\mathrm{L}$ & $17.65 \pm 6.60$ & $18.61 \pm 5.61$ & 0.082 \\
\hline \multirow[t]{2}{*}{ TES } & $\mathrm{R}$ & $17.52 \pm 7.13$ & $18.39 \pm 6.77$ & 0.189 \\
\hline & $\mathrm{L}$ & $18.87 \pm 13.38$ & $19.27 \pm 11.93$ & 0.564 \\
\hline \multirow[t]{2}{*}{ TrA-IO } & $\mathrm{R}$ & $15.39 \pm 11.46$ & $19.90 \pm 11.17$ & $<0.001^{\mathrm{a}}$ \\
\hline & $\mathrm{L}$ & $15.88 \pm 9.24$ & $20.60 \pm 9.02$ & $0.002^{\mathrm{a})}$ \\
\hline \multirow[t]{2}{*}{ EO } & $\mathrm{R}$ & $8.76 \pm 4.87$ & $10.14 \pm 3.23$ & 0.133 \\
\hline & $\mathrm{L}$ & $10.47 \pm 5.90$ & $12.22 \pm 3.23$ & 0.054 \\
\hline \multirow[t]{2}{*}{ RA } & $\mathrm{R}$ & $6.67 \pm 4.42$ & $6.93 \pm 4.01$ & 0.556 \\
\hline & $\mathrm{L}$ & $8.28 \pm 3.94$ & $8.61 \pm 3.88$ & 0.528 \\
\hline
\end{tabular}

Values are presented as mean \pm standard deviation.

MVC, maximal voluntary contraction; AH, abdominal hollowing; R, right; L, left; MF, multifidus; LES, lumbar erector spinae; TES, thoracic erect spinae; TrA-IO, transversus abdominis and obliquus internus abdominis; EO, obliquus externus abdominis; RA, rectus abdominis.

${ }^{a)} \mathrm{p}<0.05$ significantly different between stair climbing with and without abdominal hollowing according to paired t-test. 
Table 2. Local muscle to global muscle activity ratios during stair climbing with or without $\mathrm{AH}$

\begin{tabular}{ccccl}
\hline $\begin{array}{c}\text { Ratio of average } \\
\text { muscle activity }\end{array}$ & & Without AH & With AH & p-value \\
\hline MF/TES & R & $1.41 \pm 0.61$ & $1.43 \pm 0.25$ & 0.899 \\
& L & $1.56 \pm 0.08$ & $1.71 \pm 0.59$ & 0.418 \\
\hline TrA-IO/EO & R & $1.86 \pm 1.41$ & $2.58 \pm 2.38$ & $0.004^{\text {a) }}$ \\
& L & $1.60 \pm 1.14$ & $2.44 \pm 1.64$ & $0.017^{\text {a) }}$ \\
\hline TrA-IO/RA & R & $3.42 \pm 1.79$ & $3.51 \pm 1.58$ & 0.759 \\
\hline & L & $2.87 \pm 1.10$ & $2.88 \pm 1.33$ & 0.977 \\
\hline
\end{tabular}

Values are presented as mean \pm standard deviation.

$\mathrm{AH}$, abdominal hollowing; R, right; L, left; MF, multifidus; TES, thoracic erect spinae; TrA-IO, transversus abdominis and obliquus internus abdominis; EO, obliquus externus abdominis; RA, rectus abdominis.

${ }^{a} \mathrm{p}<0.05$ significantly different between stair climbing with and without abdominal hollowing according to paired t-test.

significantly higher $(\mathrm{p}<0.05)$.

\section{DISCUSSION}

This study reveals that local trunk stabilizing muscle activities during stair climbing with $\mathrm{AH}$ are greater than during stair climbing without AH. In particular, MF and TrA-IO activities, as determined by the mean values of normalized MVC data and local to global back muscle activity ratios, were greater during stair climbing with $\mathrm{AH}$, and local to global back muscle activity ratios were significantly greater for TrA-IO/EO activities. This study shows that AH during stair climbing promotes the recruitment of local trunk muscles, which suggests that this exercise type be considered for the treatment of LBP.

Many physical exercises have been developed to treat LBP [28], but the relative merits of these exercises in terms of providing effective relief remain to be clarified [28]. It is believed that lack of control of lumbar stability is a major cause of LBP $[29,30]$. Since the MF and TrA muscles play important roles in the maintenance of lumbar stability [31], training of these muscles constitutes an important component during the rehabilitation of patients with LBP $[32,33]$. Previous studies have demonstrated that asymptomatic adults activate the TrA prior to movement [34,35], but that this activation is delayed in patients with LBP [36].
$\mathrm{AH}$ is commonly used as a fundamental component of lumbar stabilization training programs [36], and is designed to facilitate the co-activations of local trunk muscles to stabilize the trunk prior to movement, which suggests that $\mathrm{AH}$ be combined with daily living activities. In addition, the activations of local trunk muscles during daily living activities have been proposed to improve lumbar spine stability [34-36]. Presently, surface EMG revealed that $\mathrm{AH}$ increased local trunk muscle stability significantly. Unpublished data from our laboratory showed that gait with $\mathrm{AH}$ effectively promoted the activities of local trunk muscles, particularly the MF and TrA-IO [37], suggesting that $\mathrm{AH}$ during functional activities and exercise can facilitate the activities of local trunk muscles known to be associated with stabilization of the lumbar spine.

Many therapeutic rehabilitation exercise strategies are based on muscle control reeducation and improving muscle performance. Segmental stabilization training of trunk muscles facilitates refinements of movement and coordination that lead to permanent improvements in movement performance. This training involves three stages of segmental control [15]. Stage 1 involves activating and facilitating the local muscle system, while using feedback to reduce the contributions of global muscles. Various feedback techniques including palpation, EMG, and real-time ultrasonography are used to simultaneously activate local muscles and inhibit global muscles. Stage 2 focuses on closed chain segmental control to improve posture and movement. The aim of this stage is to maintain local muscle synergy contraction, while gradually progressing load cues through the body using weightbearing closed chain exercise. In stage 3 , open chain segmental control is used to maintain local segmental control while load is added by open kinetic chain movement of an adjacent segment. The aim of this stage is to promote functional activities that use a combination of open and closed chain tasks. During this stage, the best way for subjects to ascertain the activations of muscles of local muscle synergy is to palpate muscles to confirm activation [14]. In the present study, contractions of local trunk muscles were confirmed by a physiotherapist by palpating TrA muscles just before stair climbing.

Real-time ultrasound imaging is a noninvasive technique that can be reliably used to measure muscle thickness. The use of real-time ultrasound biofeedback to 
learn and teach AH is more effective than verbal or cutaneous feedback [16], although the benefits of real-time ultrasound biofeedback with regard to learning AH have been questioned [15]. Nonetheless, our results show that the skills acquired to perform AH during stair climbing using real-time ultrasound biofeedback were retained.

Real-time ultrasound imaging during AH revealed substitution patterns. The presence of EO muscle contraction is thought to reflect the tonic activations of global abdominal muscles and is considered an indicator of incorrect AH [15]. In one EMG study, posterior pelvic tilt was an undesirable pattern for lumbar stabilization [38], because the activities of the RA and OE were greater than those of anterolateral abdominals during posterior pelvic tilting, and the activity of the TrA was greater than those of other abdominal muscles when lumbopelvic motion was limited [39]. Changes in foot positions during weightbearing induce alterations in pelvic tilt and lumbar lordosis [40]. However, unwanted pelvic motions have negative impacts on the activities of local trunk muscles, so increased weight-bearing through the heels could be a substitution pattern [14]. Deep inspiration followed by breath holding could also be a substitution pattern of $\mathrm{AH}$ as abdominal muscles are not involved respiration other than when expiratory flow is increased. In some people, EO activity has been observed during respiration due to overactivities of the global muscles which inversely affecting excursion of the diaphragm [14].

Presently, stair climbing with AH caused significantly more recruitment of local trunk stabilizing muscles than stair climbing without AH. Accordingly, our findings suggest that AH during daily living activities, such as stair climbing, could be therapeutic because of this selective muscle activation. Furthermore, patients with LBP that cannot find the time to participate in programmed exercises in clinics can easily perform $\mathrm{AH}$ during normal daily activities. Therefore, we believe that AH during stair climbing should be considered as an exercise for the recruitment of local trunk stabilizing muscles.

The limitations of this study include the use of surface EMG. Fine-wire EMG is accepted as the gold standard for measuring muscle recruitment [2]. But, it is invasive and presents potential complications of pain and infection, and increases cost. Thus, its applications in clinical practice are limited. The study is also limited by the recruitment of healthy subjects. Further research should be conducted to determine whether stair climbing with AH can be effectively applied to older adults with various musculoskeletal disorders, and to determine whether fine-wire needle EMG studies are required.

In conclusion, stair climbing with AH caused significantly more recruitment of local trunk stabilizing muscles than stair climbing without AH. Our findings suggest that AH during stair climbing would contribute to spinal dynamic stabilization.

\section{CONFLICT OF INTEREST}

No potential conflict of interest relevant to this article was reported.

\section{ACKNOWLEDGMENTS}

This study was supported by the Korea Healthcare Technology R\&D Project, Korea Ministry for Health, Welfare \& Family Affairs (grant no. A084177).

\section{REFERENCES}

1. Scheer SJ, Radack KL, O'Brien DR Jr. Randomized controlled trials in industrial low back pain relating to return to work. Part 2. Discogenic low back pain. Arch Phys Med Rehabil 1996;77:1189-97.

2. Ferreira ML, Ferreira PH, Latimer J, Herbert RD, Hodges PW, Jennings MD, et al. Comparison of general exercise, motor control exercise and spinal manipulative therapy for chronic low back pain: a randomized trial. Pain 2007;131:31-7.

3. Koltyn KF, Garvin AW, Gardiner RL, Nelson TF. Perception of pain following aerobic exercise. Med Sci Sports Exerc 1996;28:1418-21.

4. Sculco AD, Paup DC, Fernhall B, Sculco MJ. Effects of aerobic exercise on low back pain patients in treatment. Spine J 2001;1:95-101.

5. Meyer P, Kayser B, Mach F. Stair use for cardiovascular disease prevention. Eur J Cardiovasc Prev Rehabil 2009;16 Suppl 2:S17-8.

6. Borschmann K, Pang MY, Bernhardt J, Iuliano-Burns S. Stepping towards prevention of bone loss after stroke: a systematic review of the skeletal effects of physical activity after stroke. Int J Stroke 2012;7:330-5.

7. Granacher U, Muehlbauer T, Gruber M. A qualita- 
tive review of balance and strength performance in healthy older adults: impact for testing and training. J Aging Res 2012;2012:708905.

8. Marin R, Chang A, Cyhan T, Dinauer P. Rehabilitation implications of stepper exercise technique on exertion and hip extensor muscle activation: a small exploratory study. J Rehabil Res Dev 2008;45:125-34.

9. Souza DR, Gross MT. Comparison of vastus medialis obliquus: vastus lateralis muscle integrated electromyographic ratios between healthy subjects and patients with patellofemoral pain. Phys Ther 1991;71:310-6.

10. Bergmark A. Stability of the lumbar spine: a study in mechanical engineering. Acta Orthop Scand Suppl 1989;230:1-54.

11. Norris CM. Abdominal muscle training in sport. Br J Sports Med 1993;27:19-27.

12. Hodges PW. Is there a role for transversus abdominis in lumbo-pelvic stability? Man Ther 1999;4:74-86.

13. Souza GM, Baker LL, Powers CM. Electromyographic activity of selected trunk muscles during dynamic spine stabilization exercises. Arch Phys Med Rehabil 2001;82:1551-7.

14. Richardson C, Hodges PW, Hides J. Therapeutic exercise for lumbopelvic stabilization: a motor control approach for the treatment and prevention of low back pain. 2nd ed. Edinburgh: Churchill Livingstone; 2004.

15. Henry SM, Westervelt KC. The use of real-time ultrasound feedback in teaching abdominal hollowing exercises to healthy subjects. J Orthop Sports Phys Ther 2005;35:338-45.

16. Henry SM, Teyhen DS. Ultrasound imaging as a feedback tool in the rehabilitation of trunk muscle dysfunction for people with low back pain. J Orthop Sports Phys Ther 2007;37:627-34.

17. Hodges PW, Richardson CA. Altered trunk muscle recruitment in people with low back pain with upper limb movement at different speeds. Arch Phys Med Rehabil 1999;80:1005-12.

18. Urquhart DM, Hodges PW, Allen TJ, Story IH. Abdominal muscle recruitment during a range of voluntary exercises. Man Ther 2005;10:144-53.

19. Costa LO, Costa Lda C, Cancado RL, Oliveira Wde M, Ferreira PH. Short report: intra-tester reliability of two clinical tests of transversus abdominis muscle recruitment. Physiother Res Int 2006;11:48-50.
20. Hodges PW, Pengel LH, Herbert RD, Gandevia SC. Measurement of muscle contraction with ultrasound imaging. Muscle Nerve 2003;27:682-92.

21. Claus AP, Hides JA, Moseley GL, Hodges PW. Different ways to balance the spine: subtle changes in sagittal spinal curves affect regional muscle activity. Spine (Phila Pa 1976) 2009;34:E208-14.

22. Tsao H, Druitt TR, Schollum TM, Hodges PW. Motor training of the lumbar paraspinal muscles induces immediate changes in motor coordination in patients with recurrent low back pain. J Pain 2010;11:1120-8.

23. de Seze MP, Cazalets JR. Anatomical optimization of skin electrode placement to record electromyographic activity of erector spinae muscles. Surg Radiol Anat 2008;30:137-43.

24. Ng JK, Kippers V, Richardson CA. Muscle fibre orientation of abdominal muscles and suggested surface EMG electrode positions. Electromyogr Clin Neurophysiol 1998;38:51-8.

25. Bressel E, Dolny DG, Gibbons M. Trunk muscle activity during exercises performed on land and in water. Med Sci Sports Exerc 2011;43:1927-32.

26. Roys MS. Serious stair injuries can be prevented by improved stair design. Appl Ergon 2001;32:135-9.

27. Stevens VK, Bouche KG, Mahieu NN, Coorevits PL, Vanderstraeten GG, Danneels LA. Trunk muscle activity in healthy subjects during bridging stabilization exercises. BMC Musculoskelet Disord 2006;7:75.

28. Pfingsten M, Hildebrandt J, Leibing E, Franz C, Saur P. Effectiveness of a multimodal treatment program for chronic low-back pain. Pain 1997;73:77-85.

29. Hagins M, Adler K, Cash M, Daugherty J, Mitrani G. Effects of practice on the ability to perform lumbar stabilization exercises. J Orthop Sports Phys Ther 1999;29:546-55.

30. Nachemson AL. Instability of the lumbar spine: pathology, treatment, and clinical evaluation. Neurosurg Clin N Am 1991;2:785-90.

31. Martin PR, Rose MJ, Nichols PJ, Russell PL, Hughes IG. Physiotherapy exercises for low back pain: process and clinical outcome. Int Rehabil Med 1986;8:34-8.

32. Hides JA, Jull GA, Richardson CA. Long-term effects of specific stabilizing exercises for first-episode low back pain. Spine (Phila Pa 1976) 2001;26:E243-8.

33. Hides JA, Richardson CA, Jull GA. Multifidus muscle recovery is not automatic after resolution of acute, 
first-episode low back pain. Spine (Phila Pa 1976) 1996;21:2763-9.

34. Hodges PW, Richardson CA. Contraction of the abdominal muscles associated with movement of the lower limb. Phys Ther 1997;77:132-42.

35. Hodges PW, Richardson CA. Transversus abdominis and the superficial abdominal muscles are controlled independently in a postural task. Neurosci Lett 1999;265:91-4.

36. Hodges PW, Richardson CA. Inefficient muscular stabilization of the lumbar spine associated with low back pain: a motor control evaluation of transversus abdominis. Spine (Phila Pa 1976) 1996;21:2640-50.

37. Lee AH, Ahn SH, Cho YW, Jang SH, Jo HK, Choi HS, et al. Abdominal hollowing during gait can selectively activate local trunk stabilizing muscles. Proceedings of the 40th Annual Meeting of the Korean Academy of Rehabilitation Medicine; 2012 Oct 12-13; Seoul, Korea. 38. Richardson C, Jull G, Toppenberg R, Comerford M. Techniques for active lumbar stabilization for spinal protection: a pilot study. Aust J Physiother 1992;38:10512.

39. Vezina MJ, Hubley-Kozey CL. Muscle activation in therapeutic exercises to improve trunk stability. Arch Phys Med Rehabil 2000;81:1370-9.

40. Duval K, Lam T, Sanderson D. The mechanical relationship between the rearfoot, pelvis and low-back. Gait Posture 2010;32:637-40. 